\title{
出血で発症した高齢者脳動静脈奇形
}

\author{
橋本 宏之, 飯田 淳一, 妌井 勝也 \\ 西帚幸，榊寿右*
}

\section{Surgery for Arteriovenous Malformations in the Elderly Patients Presenting with Cerebral Hemorrhage}

Hiroyuki Hashimoto, M.D., Junichi Iida, M.D., Katsuya Masui, M.D., Noriyuki Nishi, M.D., and Toshisuke SAKAKI, M.D.*

Department of Neurosurgery, Okanami General Hospital, Ueno, and *Department of Neurosurgery, Nara Medical University, Kashihara, Japan

Summary: Arteriovenous malformations (AVMs) in elderly patients are rare. The natural history of AVMs in elderly patients has not been well known. We report 2 cases of AVMs of elderly patients presenting with a cerebral hemorrhage. Both of them were surgically excised with a satisfactory outcome.

Case 1 was a 75-year-old man who presented with right frontal hemorrhage. Cerebral angiography disclosed an undefined vascular lesion. A thrombosed AVM was identified during surgery, and was proven by histological examination of the surgical specimen.

Case 2 was a 72-year-old man who had a history of mild right hemiparesis from early childhood. He presented with a left frontal hemorrhage. Cerebral angiography showed an AVM in the left mortor cortex. He left the hospital with a neurological recovery to the level before the onset. AVMs in elderly patients may be prone to bleed. Surgical treatment of AVMs in elderly patients might be a useful option when they are easily accessible.

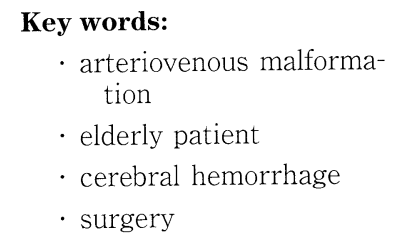

Surg Cereb Stroke (Jpn) 25: 386-390, 1997

\section{はじめに}

脳動静脈奇形は高齢者で発見されることは少なく，大部 分が40歳までに発症するといわれている ${ }^{10) 13) 14)}$ 。ことに 脳動静脈奇形が出血で発症することは中年期以降少なくな り高齢者ではまれであると考えられてきた ${ }^{11) 13) 14) . ~}$

また高齢者の場合，脳動静脈奇形の自然経過と外科的治 療の危険性を考えて今までは保存的治療が推奨されてきた
3)6)8)9) 11)17). ところが，最近 Harbaugh ら ${ }^{7)}$ は高齢者脳動 静脈奇形といえども出血することがまれではなく外科治療 の対象になりうると報告した。今回, 我々も出血で発症し た2例の高齢者脳動静脈奇形を経験し摘出術により良好な 結果を得たので若干の文献的考察を加えて報告する。

\section{症例}

$<$ 症例 $1>75$ 歳, 男性.

岡波総合病院 脳神経外科, *奈良県立医科大学 脑神経外科(受稿日 1996.12.6)〔連絡先：干518 三重県上野市桑町 1734 岡波総合 病院 脳神経外科橋本宏之] [Mailing address: Hiroyuki HASHImoTo, M.D., Department of Neurosurgery, Okanami General Hospital, 1734 Kuwa-machi, Ueno, Mie 518, Japan] 


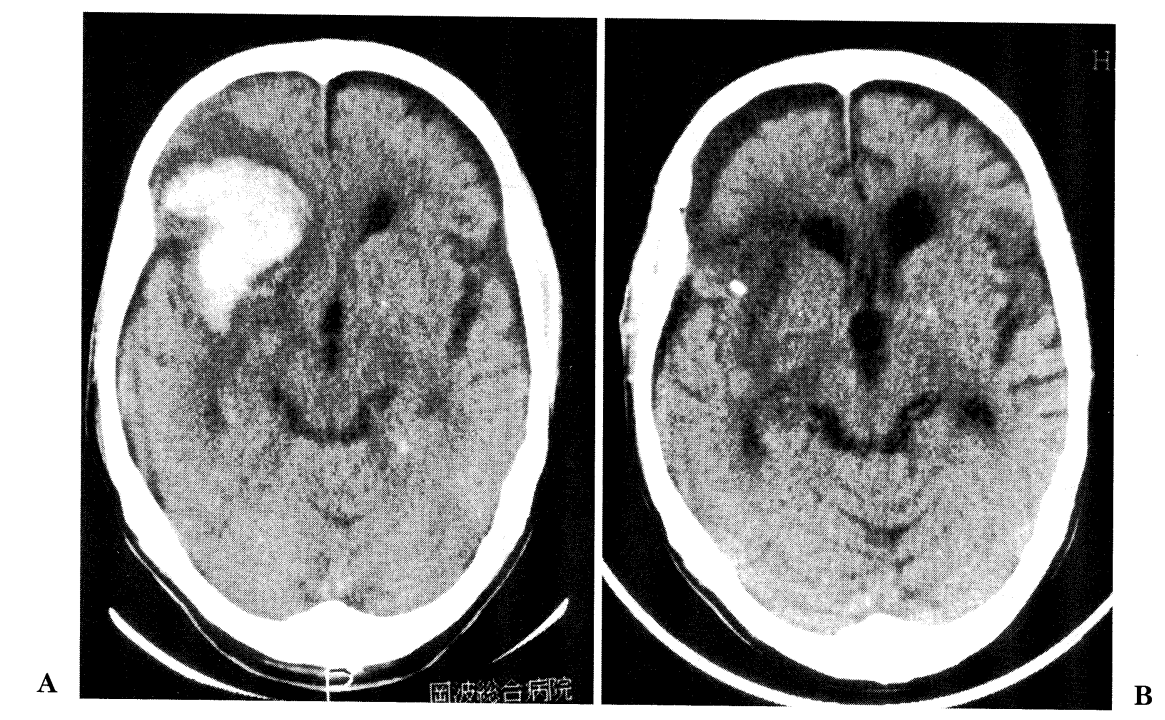

Fig. 1 A: CT scan on admission showed right frontal hemorrhage. B: Postoperative CT scan showed uneventful course after surgery.

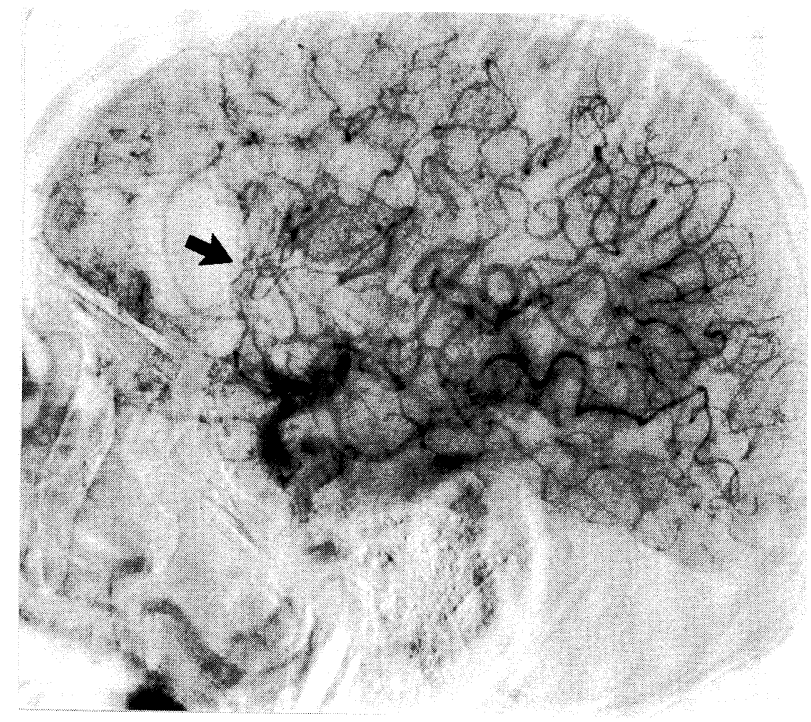

Fig. 2 Preoperative right carotid angiography shows an undefined vascular lesion consisted of abnormal vessels (arrow).

主 訴: 意識障害.

家族歴，既往歴：特記すべき事項なし.

現病歴：1992年 4 月, 突然の頭痛に続いた意識障害で 発症し他院に救急搬送される。意識状態は徐々に改善して きたが，CTにて脳内出血を認めたので当科に紹介され入 院となる.

入院時現症: 軽度失見当識と左片麻㾝 $3 / 5$ を認めた。

神経放射線学的所見：単純CT(Fig. 1A)では右前頭葉に 約 $4 \mathrm{~cm}$ の出血を認めたが造影 CTでは明らかな増強はみ
られなかった，血管撮影では明らかな脳動静脈奇形とは断 定できないが右前頭葉に異常な血管の集簇がみられた (Fig. 2). 以上のことから血栓性脳動静脈奇形あるいは何 らかの血管性病変からの出血を疑った。

手 術：血腫および血管性病変の摘出を行うべく通常の 右前頭側頭開頭を行った。血腫を除去していくと約 $2.5 \mathrm{~cm}$ の結節性の組織化した異常血管の塊を認め血栓化した脳動 静脈奇形と断定した。流入動脈は中大脳動脈から数本みら れ可及的に病変を摘出した。

組織学的所見：血栓化した大小不同の異常血管からなり 血栓性脳動静脈奇形と診断された(Fig. 3).

術後経過: 術前みられた左片麻痺や失見当識は徐々に改 善し独歩退院した(Fig. 1B).

$<$ 症例 $2>72$ 歳, 男性.

主 訴: 意識障害.

家族歴：特記事項なし.

既往歴：幼少時より右上下肢の運動障害がみられ小児麻 痺と診断されていた。 3 年前より脳梗塞の疑いで他科に通 院していたがCTで左前頭葉の異常な石灰化を指摘されて いた(Fig. 4A).

現病歴：1995年 9 月, 突然の意識障害と右上肢運動障 害の増悪を認め当科に救急搬送されてきた。

入院時現症：運動性失語症，右片麻盘 $2 / 5$.

神経放射線学的所見: 単純 CTでは以前から指摘されて いた左前頭葉の石灰化に接して $3 \mathrm{~cm}$ の脳内血腫を認めた (Fig. 4B). 血管撮影では左内頸動脈写にて運動野の石疢化 に一致して $2 \mathrm{~cm}$ の脳動静脈奇形を認めた(Fig. 5A). 動静 


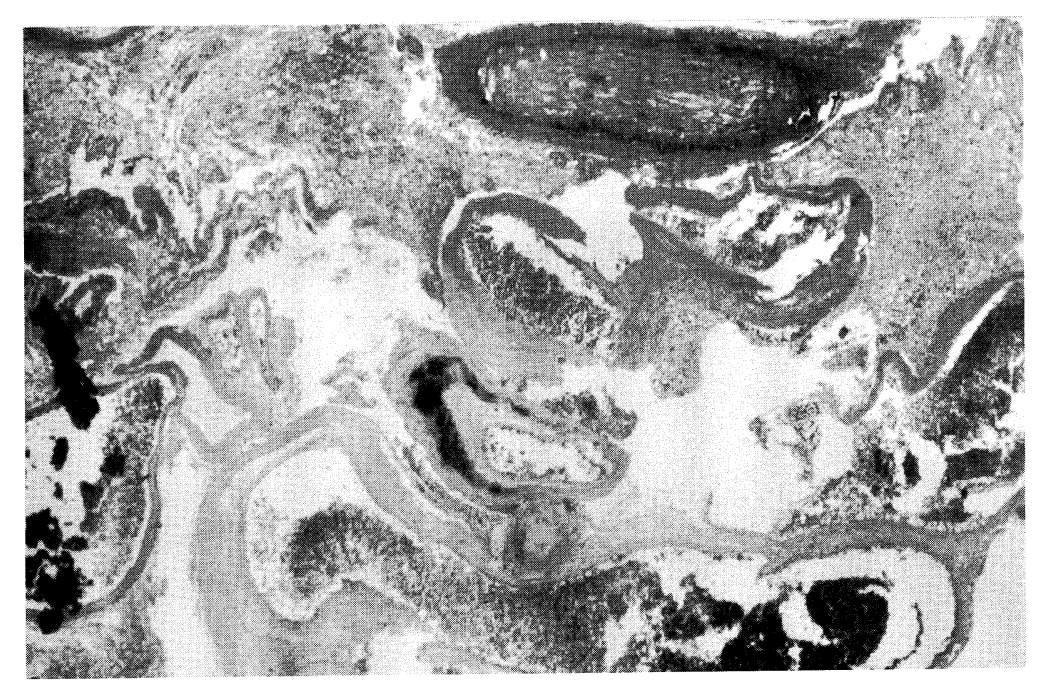

Fig. 3 Microsection of the surgical specimen in the case 1 showed thrombosed arteriovenous malformation consisting of abnormal dilated arteries and veins (hematoxylin-eosin stain $\times 200$ ).
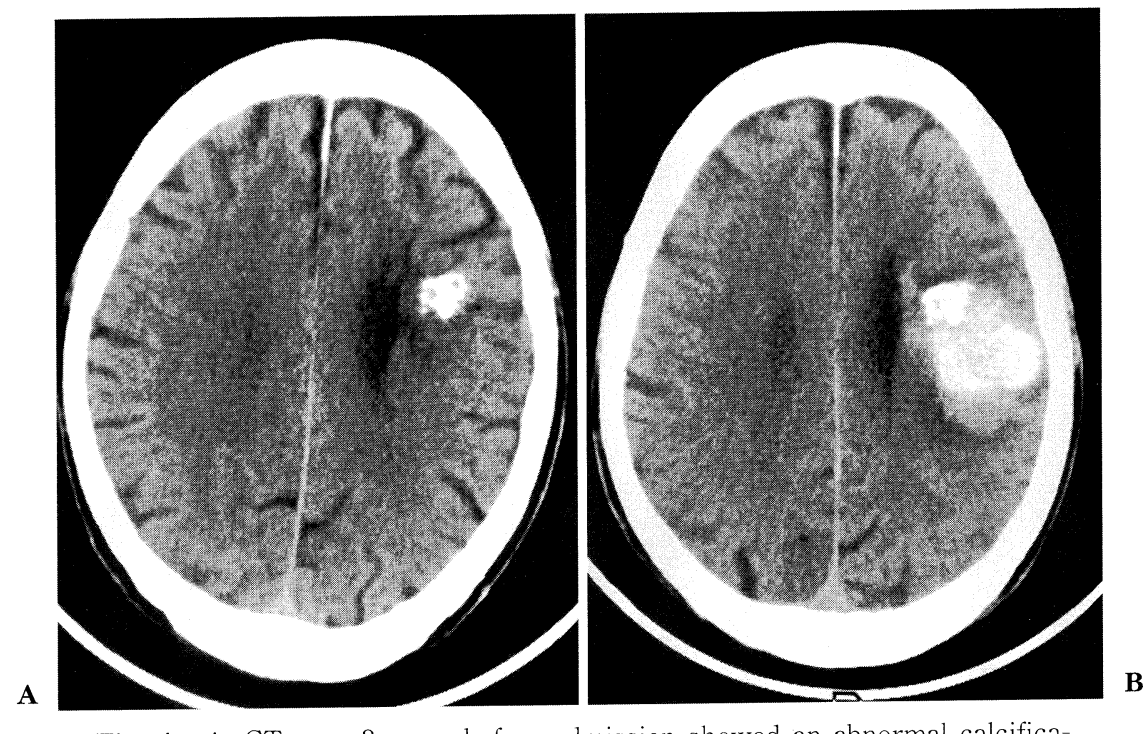

Fig. 4 A: CT scan 3 years before admission showed an abnormal calcification and low density area in the left frontal lobe. B: CT scan on admission showed a hemorrhage closely to the calcification.

脈奇形の循環時間は通常に比べて少し遅延していた。

手 術：上矢状洞に合流する流出静脈を逆行性にたどり 中心溝から nidusに到達する。中心溝の底部から血腫腔に いたり可及的に血腫除去を行った。続いて石扊化した動静 脈奇形を全摘出した。

術後経過：経過は良好で術前にみられた失語症や右片麻 痺は改善し独歩退院した(Fig. 5B).

\section{考察}

脳動静脈奇形を治療する場合，この病態の自然経過は当 然，熟知しておかなければならない. 現在までの脳動静脈 奇形の自然経過に関する研究では母集団に含まれる高齢者 は非常に少なく，高齢者に限っていえば自然経過はいまだ 不明である 1)3)4)12).

高齢者脳動静脈奇形が絶対的に少ない理由は以下のよう に考えられている。まず大部分の症例が若いうちに症候性 

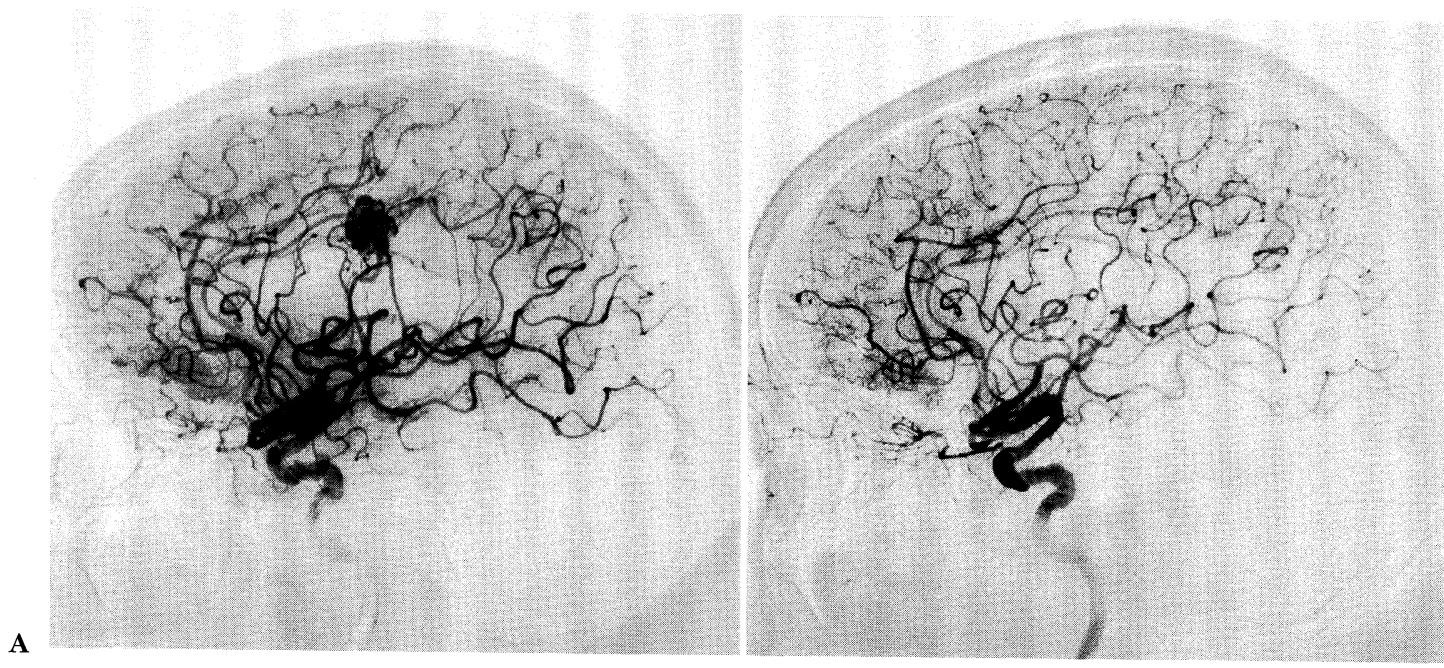

Fig. 5 A: Preoperative angiogram disclosed a small arteriovenous malformation in the mortor cortex. B: Postoperative angiogram showed a complete resection of the arteriovenous malformation.

となり未治療のままで高齢になることは少ない，高齢者で は出血した場合でもアミロイドアンギオパチーや高血圧が 原因と考えられ見過ごされている可能性がある。さらにた とえ診断にいたっても高齢であるがゆえに外科的治療の対 象としては紹介されてこない可能性も考元られている77.

しかし一般的には高齢者脳動静脈奇形は臨床的には比較 的安全と考元られ保存的治療が推奨されてきた ${ }^{8) ~-10) . ~}$ 。 ころが最近, Harbaugh ${ }^{7}$ は65歳以上の出血で発症した 症例を提示し，高齢者での脳動静脈奇形の出血の危険性と 外科治療の必要性を示唆している.今回, 我々も同様に出 血を生じた 2 例の高齢者脳動静脈奇形を経験した.

症例 1 は術前血管撮影では確定診断はできなかったが血 栓性脳動静脈奇形あるいは何らかの血管性病変からの出血 を疑い手術に踏み切った。術中所見と組織学的所見から最 終的に脳動静脈奇形と診断した。つまり血栓化された脳動 静脈奇形が高齢になってはじめて出血したものと考えられ た。症例 2 は生来, 右軽度片麻疩を認妃肾麻痺と診断さ れていた興味深い症例である。当科受診 3 年前にすでに他 科に扔いてCTで左前頭葉の異常な石灰化を指摘されてい たが特別な治療なしに放置されていた。今回，72歳にし て初めて出血で発症した症例である。以上， 2 症例とも高 齢ではあったが動静脈奇形が小さく表在性で比較的容易に 摘出することができ良好な結果が得られた。 Luessenhop と Rosa ${ }^{10)}$ は脳動静脈奇形の年間の出血率は 2 〜 4\%であるから高齢者の脳動静脈奇形は保存的加療が良 いと述べている。他方, Graf $~^{5)}$ は65歳以上の脳動静脈奇 形が発症した場合はすべて出血であったと報告している. またCrawford ら ${ }^{1)}$ 診断時, 60 歳以上の11例の脳動静脈
奇形に扔いて経過観察すると8 例に出血が起こったと報告 した。以上のことは未治療の高齢者脳動静脈奇形では年間 出血率は 2 4 \%より高い可能性を示唆している. しかし 他方に押いて脳動静脈奇形の自然消退率がいまだ明らかで はないので正確な高齢者脳動静脈奇形の出血率は算定でき ない。

高齢者脳動静脈奇形を治療するうえで血管内治療や定位 的放射線治療の方が外科的治療より安全で望ましいと示唆 する報告がみられる ${ }^{16)}$. しかし高齢者脳動静脈奇形の年 間出血率が $10 \%$ に達すれば顕微鏡下摘出術の危険性の方 が他の治療での出血する危険性より少ないとする報告もあ $ろ^{7)}$. 今回, 我々は出血を示した 2 例の高齢者脳動静脈奇 形を経験し摘出術により良好な結果が得られた，患者の全 身状態が良く表在性で小さいものであれば高齢者でも手術 を考慮する必要があると思われた。しかしながら最終的な 結論を出すにはさらに多くの症例を重ねた高齢者脳動静脈 奇形での疫学的な検討が必要である.

\section{結語}

1. 出血で発症した 2 例の高齢者脳動静脈奇形を経験し外 科的摘出術により良好な結果を得ることができた。

2. 高齢者の脳内出血においても脳動静脈奇形破裂を考慮 にいれて適切な治療を行う必要がある.

3. 全身状態が良く脳動静脈奇形が表在性で小さければ高 齢者でも外科的治療を考慮する必要がある。

\section{文献}

1) Crawford PM, West CR, Chadwick DW, et al: Arteriovenous 
malformations of the brain: Natural history in unoperated patients. J Neurol Neurosurg Psychiatry 49: 1-10, 1986

2) Debrun G, Vinuela F, Fox A, et al: Embolization of cerebral arteriovenous malformations with bucrylate: Experience in 46 cases. J Neurosurg 56: 615-627, 1982

3) Forster DMC, Steiner L, Hakanson S: Arteriovenous malformations of the brain: A long-term clinical study. J Neurosurg 37: 562-570, 1972

4) Fults D, Kelly DL Jr: Natural history of arteriovenous malformations of the brain: A clinical study. Neurosurgery 15: 658-662, 1984

5) Graf CJ, Perret GE, Torner JC: Bleeding from cerebral arteriovenous malformations as part of their natural history. J Neurosurg 58: 331-337, 1983

6) Guidetti B, Delitala A: Intracranial malformations: Conservative and surgical treatment. J Neurosurg 53: 149152, 1980

7) Harbaugh KS, Harbaugh RE: Arteriovenous malformations in elderly patients. Neurosurgery 35: 579-584, 1994

8) Heros RC, Tu YK: Is surgical therapy needed for unruptured arteriovenous malformations? Neurology 37: 279-286, 1987

9) Luessenhop AJ: Cerebral arteriovenous malformations. Part I. Contemp Neurosurg 11, 1989

10) Luessennhop AJ, Rosa L: Cerebral arteriovenous malforma- tions: Indications for and results of surgery, and the role of intravascular techniques. J Neurosurg 60: 14-22, 1984

11) Moody RA, Poppen JL: Arteriovenous malformations. J Neurosurg 32: 503-511, 1970

12) Ondra SL, Troupp H, George ED, et al: The natural history of symptomatic arteriovenous malformations of the brain: A 24-year follow up assessment. J Neurosurg 73: 387-391, 1990

13) Parkinson D, Bachers G: Arteriovenous malformations. Summary of 100 consecutive supratentorial cases. J Neurosurg 53: 285-299, 1980

14) Perret G, Nishioka H: Report on the cooperative study of intracranial aneurysms and subarachnoid hemorrhage. Section VI: Arteriovenous malformations. J Neurosurg 25: 467-490, 1966

15) Steiner L, Lindquist $C$, Adler JR, et al: Clinical outcome of radiosurgery for cerebral arteriovenous malformations. J Neurosurg 77: 1-8, 1992

16) Steiner L, Lindquist C, Cail W, Karlsson B, Steiner M: Microsurgery and radiosurgery in brain arteriovenous malformations. J Neurosurg 79: 647-652, 1993

17) Wilkins RH: Natural history of intracranial vascular malformations: A review. Neurosurgery 16: 421-430, 1985 